\title{
O respeito à diversidade étnica e cultural dos alunos: uma intervenção no campo dos direitos humanos
}

Respect to diversity ethnic and cultural of students:

An intervention in the field of human rights

Elizabeth Christina Rodrigues Bittencourt ${ }^{1}$

\section{RESUMO}

O objetivo principal deste trabalho é o de reconhecimento da diversidade étnica e cultural de um grupo de alunos de $9^{\circ}$ do ensino fundamental de uma escola municipal da cidade de São Paulo. Situa-se no campo das Ciências Humanas, possuindo um caráter exploratório, caracterizado por um projeto de intervenção no campo da Educação em Direitos Humanos. A partir disso, percebemos que uma simples alteração na "forma escolar", dentro do ambiente restrito de uma sala de aula padronizada da escola, possibilitou a ampliação da rede de relações colaborativas entre os alunos.

\section{PALAVRAS-CHAVE}

Direitos Humanos. Diversidade étnica e cultural. Projeto de intervenção

\footnotetext{
${ }^{1}$ EMEF Bernardo Higgins.
} 


\section{ABSTRACT}

The main objective of this work is the recognition of ethnic and cultural diversity of a group of 9th elementary school students of a municipal school in the city of São Paulo. It lies in the field of Humanities, having an exploratory nature, characterized by an intervention project in the field of Human Rights Education. From that, we realized that a simple change in the "school form", within the restricted environment of a standardized school class room, enabled the expansion of the network of collaborative relationships among students.

\section{KEY WORDS:}

Human rights. Ethnic and cultural diversity. Intervention Project. 


\section{INTRODUÇÃO}

Nem todos os homens são felizes, mas todos têm direito a sê-lo. (KANT, 2004)

Ao olhar em nossa volta, no transcurso de nossas vidas, podemos observar pessoas tristes e desiludidas, e algumas vezes conseguimos entender a razão disso. Em uma viagem que fiz, acompanhada de minha filha a Manaus, visitamos uma tribo indígena na margem oposta do Rio Negro e durante algumas horas pudemos estar mais próximas de seu ambiente natural. Nesta condição particular, passamos de maioria ao papel de minoria, e observamos e escutamos o que eles tinham para dizer. Ao assistir o documentário "Índios no Brasil" (SEF/SEED/FUNDESCOLA, 2013) durante o Curso Educação em Direitos Humanos fez com que estas lembranças fossem reforçadas e as palavras que ouvimos ganharam eco, ganhando outro significado, me levando a aprofundar estudos que permitissem esclarecer a situação problemática em que vivem, tanto em seu ambiente natural quanto no ambiente urbano, e principalmente nas escolas, onde atuo profissionalmente. Nela, esta proposta se justifica pelo fato de que muitos conflitos surgem entre os alunos, quando deixam de reconhecer no colega, aluno de origem indígena, um sujeito de direitos, tanto no direito à Educação quanto à sua identidade étnico-cultural.

Alguns relatos, que refletem a ação dos professores empenhados em desenvolver uma cultura de Direitos Humanos perante suas turmas, já foram publicados e refletem o empenho da Secretaria Municipal de Direitos Humanos e Cidadania da cidade de São Paulo (CARBONARI et all, 2014).

Desta forma, a Educação em Direitos Humanos passa a ser a via de se oferecer igualdade de oportunidades pela educação, conforme defendeu Anísio Teixeira, em seu projeto para a Bahia: "Nascemos desiguais, nascemos ignorantes, e, portanto, nascemos escravos. É a educação que pode mudar". (TEIXEIRA, 1947 in BENEVIDES, 1998, p. 159) A citação de Anísio Teixeira nos remete diretamente ao período que se sucedeu ao final da Segunda Guerra Mundial, que tantas vidas havia ceifado e tantas marcas deixado pelo mundo antes em combate. $O$ horror à guerra estava instaurado e se buscava ansiosamente o caminho da reconstrução dos países, alicerçados em princípios de coexistência pacífica e proteção dos direitos humanos. Em dezembro de 1948, em sessão realizada em Paris, a Assembleia Geral das Nações Unidas aprovou, pelo voto de 48 países, dentre eles o Brasil, que adotou e proclamou a Declaração Universal dos Direitos Humanos, documento válido e respeitado até os dias de hoje. Ela está expressa, nos Temas Transversais dos Parâmetros Curriculares Nacionais (PCNs), especialmente nos Temas: Ética, Pluralidade Cultural e Meio Ambiente. (MEC/SEF, 1998)

Este trabalho pretende, dentro do campo dos Direitos Humanos, manter o foco no modelo de pesquisa qualitativa, dentro das Ciências Humanas e Sociais segundo Chizzotti (2000). Este autor defende que "a abordagem qualitativa parte do fundamento de que há uma relação dinâmica entre o mundo real e o sujeito", no qual o sujeito-observador é parte integrante do processo de conhecimento e interpreta os fenômenos, atribuindo-lhes um significado (CHIZZOTTI, 2000, p. 79). Em um entendimento mais específico, segundo Antonio Carlos Gil, situa-se no campo das pesquisas aplicadas, que estão fundamentadas nas pesquisas acadêmicas que proporcionam o avanço das ciências, mas com a preocupação de "aplicação imediata numa realidade circunstancial" (GIL, 2008, p. 27). Assim sendo, tem um caráter exploratório, pois busca aproximar a teoria da prática, sendo o primeiro passo para uma investigação mais ampla, com os próprios instrumentos aperfeiçoados. A intervenção pedagógica (DAMIANI et all., 2013) foi realizada com os alunos de uma turma do último ano do Ensino Fundamental na Escola Municipal de Ensino Fundamental Bernardo O'Higgins, subordinada à Diretoria de Ensino Santo Amaro, Zona Sul da cidade de São Paulo.

A organização geral deste trabalho compreende quatro capítulos, sendo que o primeiro se inicia com o entendimento das relações de poder que acontecem entre os alunos, que decorrem da diversidade étnica e cultural presente nas escolas. Sob o ponto de vista constitucional, a "matriz indígena" é fortemente desfavorecida, pois o indígena brasileiro ao nascer já se encontra sob o regime de tutela do Estado. A defesa dos seus direitos, previstos no Estatu- 
to do Índio ainda são insuficientes para conter a violência, como no crime perpetrado contra o índio Galdino, em 1997. A condição de "exclusão social" que estigmatiza os indígenas atinge também outros migrantes, imigrantes, exilados e refugiados. Para entender todas estas possibilidades foi necessário buscar na "Teoria das Representações Sociais" e na "Psicologia das Minorias Ativas" outros subsídios teóricos para reflexão e o entendimento destes efeitos nas comunidades escolares. A relação pedagógica existente entre "mestre" e "alunos" passa a ser estudada como o modelo de socialização dominante e suas propostas de ação interativas, que ofereçam coexistência respeitosa entre indivíduos e grupos de diferentes origens étnicas e culturais.

O segundo capítulo se inicia com a retomada da diversidade étnica e cultural que constitui o povo brasileiro, e as dificuldades das relações interpessoais. A escola passa a ser considerada como o ambiente onde "o modo escolar de socialização é o modo de socialização largamente e hegemônico" de nossas formações sociais (VINCENT; LAHIRE, THIN, 2001, p. 38). Desta forma os esforços desenvolvidos pelo corpo docente, sob orientação da equipe gestora, ficam entendidos neste sentido, adequando projetos e ações à realidade das comunidades onde estão localizadas, favorecendo a socialização dos alunos. A escola onde foi desenvolvido o projeto de intervenção docente passa a ser descrita, desde seu histórico, espaço e tempo escolar, normas e regulamentos, práticas escolares e a sala de aula, em sua distribuição espacial e desenvolvimento do Projeto Pedagógico.

No terceiro capítulo serão apresentados os principais aspectos considerados para a elaboração e desenvolvimento do projeto de intervenção, desde seus objetivos e métodos até os primeiros resultados obtidos. Importante ressaltar que, pela exiguidade de tempo no planejamento das ações, e por se tratar de uma pesquisa exploratória, sem referencial teórico que subsidiasse as ações, especialmente quanto à elaboração das "questões iniciais", muito do que foi feito deverá ser revisto, caso haja interesse desta escola, ou de outras, que porventura tenham interesse em desenvolver um projeto semelhante. Convém considerar que as ações que provocaram o rearranjo dos alunos em "pequenos grupos", na segunda etapa do projeto, o que os levou a formar vínculos com colegas com os quais tinham pouco relacionamento, seguiram práticas pedagógicas consolidadas no cotidiano escolar, o que em muito favoreceu os resultados favoráveis obtidos, descritos brevemente no quarto capítulo.

Este trabalho, desenvolvido a partir de um projeto que estava fortemente fundamentado na diversidade étnica e cultural dos alunos, acabou ganhando, durante sua realização, uma característica mais ampla, de reconhecimento das qualidades próprias de cada aluno, como indivíduo, e reconhecimento no "outro", seu colega, um parceiro em potencial, com o qual é possível a divisão de tarefas em um trabalho conjunto. Poderão, em suma, garantir o direito da identidade individual e do reconhecimento da alteridade do colega, atendendo aos ditames das normas de respeito e convivência da escola.

Um protótipo do questionário a ser aplicado aos alunos dos três turnos da escola observou o preceito adotado no Censo 2010 do IBGE (IBGE, 2010, p. 15) de autoidentificação étnico-racial, além de aproximação com termos da língua falada e outros valores culturais. Pretende reconhecer não somente os indivíduos dos povos indígenas, mas também identificar os alunos em sua diversidade étnica e cultural, para a proposição de estudos complementares e valorização da diversidade existente.

Este protótipo será encaminhado à equipe de direção da escola, para que discuta sua validade, com ou sem modificações por parte do corpo docente, para ulterior aplicação, com autorização do ConseIho de Escola.

\section{1 - EDUCAÇÃO EM DIREITOS HUMANOS E O RESPEITO À DIVERSIDADE}

As desigualdades sociais são, muitas vezes, justificadas pela cor da pele, pelo tipo de cabelo e outras características físicas, a partir das quais um determinado grupo é tomado como "superior" ou "inferior", supostamente "bom" ou "mau", "civilizado" ou não. As temáticas vinculadas à raça e à etnia ligam-se, portanto, a relações de poder estabelecidas social e historicamente. (PMSP/SME/ FAFE, 2006) 
Ao se buscar o entendimento das relações de poder que se expressam entre os alunos, individualmente, ou entre grupos de alunos com características diferentes, as questões ligadas às diversas etnias presentes na escola e em todas as salas de aula logo se apresentaram relevantes. A formação do povo brasileiro, no entendimento de Darcy Ribeiro (1995, p. 19) foi determinada pela "confluência, do entrechoque e do caldeamento do invasor português com índios silvícolas e campineiros com negros africanos". Este é o conhecido "mito das três raças", que, mesmo questionado no campo da Antropologia, serviu de suporte aos primeiros censos realizados pelo Instituto Brasileiro de Geografia e Estatística (IBGE). Renato Sztutman (2008) apresenta esta inversão no quadro das grandes interpretações do Brasil, garantindo a Darcy Ribeiro o papel de "divisar a maloca indígena no fundo da paisagem da casa grande e senzala" (2008: 18).

Entretanto, uma grande disparidade se apresenta ao se analisar a condição do direito dos índios quanto à ocupação e demarcação do território que ocupam depois da chegada dos europeus e outros estrangeiros ao país (FERRAZ JUNIOR, 2004). A Carta de 1988, conhecida como "Constituição Cidadã", foi toda pensada na prevalência do interesse social, e a propriedade foi reconhecida como um direito fundamental dos brasileiros e estrangeiros aqui residentes. Ela refere, em seu artigo 20, que as terras tradicionalmente ocupadas pelos indígenas são bens da União. Mais ainda, conforme considera Souza e Barbosa (2011):

[para] ...compreensão da situação jurídica dos índios no Brasil, o disciplinamento de sua capacidade por designação do Código Civil de 2002 (artigo 4º, parágrafo único), encontra-se disciplinada no Estatuto do Índio (Lei n. 6.001/73), segundo o qual o indígena brasileiro ao nascer já se encontra sob o regime de tutela sendo incapaz para os atos da vida civil até que atenda certos requisitos (artigo $9^{\circ}$, Lei n. 6.001/73) e torne-se livre desse regime. Tal situação afeta diretamente o efetivo exercício dos direitos indígenas por seus titulares, se revelando como expressão típica do sistema de integração defendido por tal legislação.

As terras indígenas representam $12,5 \%$ do território brasileiro, segundo dados transcritos abaixo, fornecidos pelo Censo de 2010 do IBGE (IBGE, 2010, p. 17):

Número de terras indigenas e superfície, segundo a situação fundiária Brasil - 2010

\section{Situação fundiária}

\section{Total}

Declarada

Homologada

Regularizada

Em processo de aquisição como Reserva Indígena

\begin{tabular}{|c|r|}
\hline \multicolumn{2}{|c|}{ Terras Indigenas } \\
\hline Número & Superfície (ha) \\
\hline $\mathbf{5 0 5}$ & $\mathbf{1 0 6 7 3 9 ~ 9 2 6}$ \\
\hline 49 & 2689068 \\
\hline 27 & 4761768 \\
\hline 405 & 99240734 \\
\hline 24 & 48347 \\
\hline
\end{tabular}

\section{Fonte: Fundaçăo Nacional do Índio - FUNAI}

Quadro 1 - Número de terras indígenas e superfície (IBGE, 2010)

Observando o Cartograma que acompanha este Quadro (Figura 1), pode-se notar que as terras indígenas estão localizadas principalmente na região norte do País (IBGE, 2010, p. 18): 


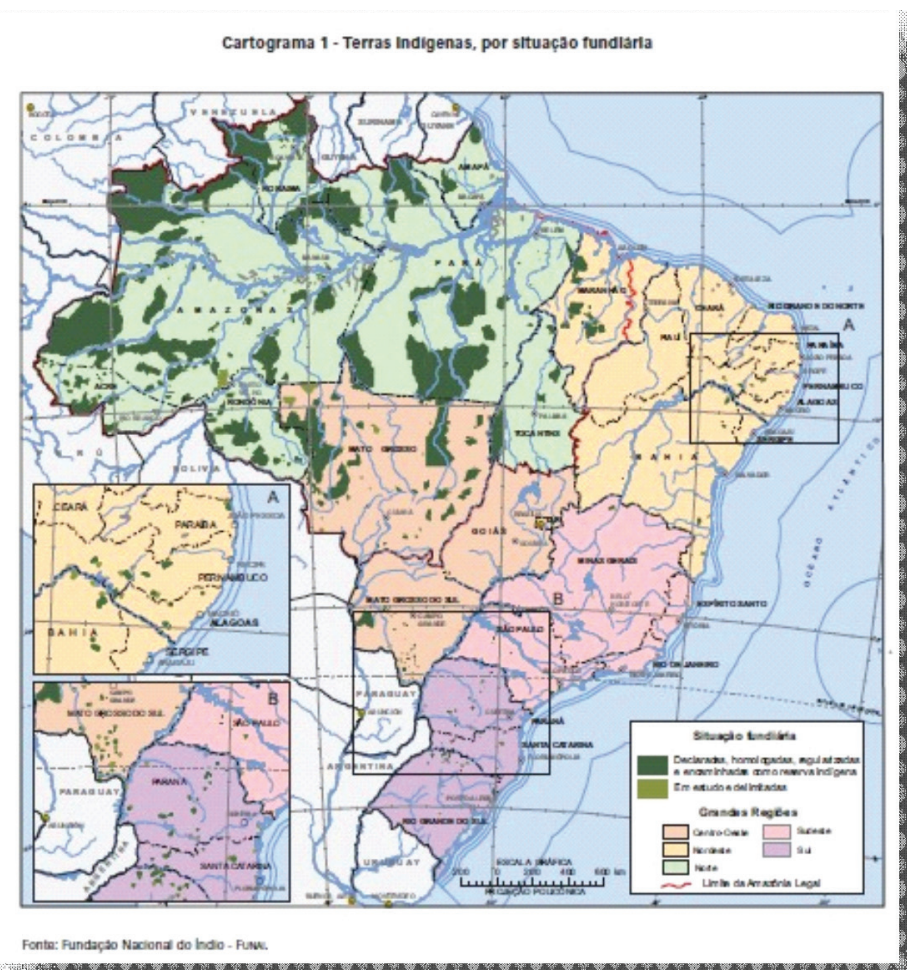

Figura 1 - Terras indígenas no território brasileiro

De acordo com os resultados do Censo Demográfico 2010 provenientes do quesito cor ou raça, 817,9 mil pessoas se declararam indígenas, representando $0,4 \%$ da população total do Brasil. Por uma série de fatores, a obtenção de informações sobre a identidade indígena é complexa. Dependendo do contexto, membros de uma dada etnia podem ter receio de manifestar sua identidade, seja por preconceito e discriminação, ou mesmo negar o pertencimento étnico possivelmente devido às experiências vividas anteriormente. Desses, 36,2\% residiam na área urbana e 63,8\% na rural. Enquanto na área urbana, a Região Sudeste deteve o maior percentual de indígenas (80\%), a Região Norte, com $82 \%$, foi o maior percentual da área rural. (IBGE, 2010, p. 52-54)

Apesar do extermínio sofrido, muitas populações indígenas resistiram e atualmente sua luta vem sendo reconhecida em todo território nacional. A questão das "terras indígenas" vem mobilizando desde há muito tempo os representantes dos diferentes povos indígenas, em busca de salvaguardar seus direitos de ocupação da terra, que era ocupada sem restrições desde antes da chegada dos primeiros eu- ropeus. Entretanto, alguns fatos ainda chocam o cenário nacional:

O assassinato do índio pataxó hãhãhãe Galdino Jesus dos Santos, em 20 de abril de 1997, queimado vivo enquanto dormia em uma parada de ônibus no centro de Brasília, provocou reações de perplexidade na sociedade brasileira. (PIUBELLI, 2012)

Um crime de homicídio triplamente qualificado por motivo torpe, meio cruel e uso de recurso que impossibilitou defesa à vítima. A descrição minuciosa dos relatos, das memórias em torno de Galdino e sua luta pela demarcação das terras indígenas é continuada pela interpretação das autoridades públicas, dos índios e membros da sociedade civil. A repercussão em todo o Brasil foi enorme e desvelou o aumento considerável nas taxas de homicídios cometidos por jovens do Distrito Federal entre 1979 e 1995 . Oito instituições, além da UNESCO participaram de uma ampla pesquisa, que resultaram na publicação do livro "Juventude, violência e Cidadania: os jovens de Brasília" (WAISELFISZ, UNESCO, 1998), ao final da qual os pesquisadores puderam recomendar um conjunto de ações preventivas por parte dos órgãos públicos, pais 
e educadores de todo o país no combate à violência.

A situação dos indivíduos indígenas, como no caso citado, remete aos estudos sociológicos de "exclusão social". Avelino da Rosa Oliveira (2000, p. 87) lembra que, quando se estuda o par cidadania-educação encontramos, na outra face da mesma moeda, a educação-exclusão. Este autor afirma que este é um campo que tem de ser estudado muito além do campo estrito da Educação, passando ao panorama socioeconômico das sociedades contemporâneas, ou seja, da Sociologia e da condição econômica em que estão situados os sujeitos objetos dos estudos. Após percorrer extensa bibliografia, indica que, no estudo da sociologia do desvio, que dá origem às ocorrências de casos de violência deste tipo, indica o estudo de uma das obras centrais neste campo, de autoria de Howard Becker, publicado originalmente em 1963 e posteriormente traduzido e publicado no Brasil. O título - Outsiders - remete ao conceito a respeito de indivíduos que não se conduzem segundo as regras acordadas pelo grupo. Becker faz as seguintes considerações a este respeito (BECKER, 2007, p. 15):

Todos os grupos sociais fazem regras e tentam, em certos momentos e em algumas circunstâncias, impô-las. Regras sociais definem situações e tipos de comportamentos a elas apropriados, especificando algumas ações "certas" e proibindo outras como "erradas". Quando uma regra é imposta, a pessoa que presumivelmente a infringiu pode ser vista como um tipo especial, alguém de quem não se espera viver com as regras estipuladas pelo grupo. Esta pessoa é encarada como um outsider.

De toda forma, o conceito de outsiders - "indivíduos que não se conduzem segundo as regras acordadas pelo grupo" - definido por Becker (2007, p. $17)$ é aceito por Oliveira (2000, p.100) e outros pesquisadores nas ciências sociais. É possível entender que este termo se aplica aos indivíduos, ou grupo de indivíduos que estão afastados de seu ambiente cultural original, e isto oferece uma visão mais ampla para o problema dos povos indígenas e seus descendentes quando deslocados das terras indígenas demarcadas institucionalmente. Todos os migrantes, imigrantes, exilados e refugiados podem também reconhecidos como outsiders, pois ficaram deslocados perante a população local assim que chegaram a seu destino atual. Trazem consigo traços de suas culturas originais e se destacam em relação à comunidade local, o que pode gerar estranhamento, preconceito e violência, nos casos mais extremos, como no caso do índio Galdino.

Na perspectiva das ciências sociais, o índio Galdino estava em busca dos interesses dos povos indígenas, o que remete a dois campos complementares do conhecimento, ambos equivalentes e de igual importância:

$1^{\circ}$ ) às "Representações Sociais", através da "Teoria das Representações Sociais", definida por Jovchelovitch da seguinte forma:

A TEORIA DAS REPRESENTAÇÕES SOCIAIS se articu-
la tanto com a vida coletiva de uma sociedade, co-
mo com os processos de constituição simbólica, nos
quais os sujeitos sociais lutam para dar sentido ao
mundo, entendê-lo e nele encontrar o seu lugar,
através de uma identidade social. (JOVCHELOVI-
TCH, 2003, p. 65)

Um indivíduo, ou sujeito, ao assumir o papel de um "representante social" assume para si o papel de defender pessoalmente os interesses do grupo social que representa e, consequentemente, os riscos que disso advém, pois em muitas situações está distante de seu ambiente nativo, ou natural. É a situação a que se expôs o índio Galdino, ao distanciar-se de seu grupo, à margem de sua comunidade, vítima de jovens de comportamento desviante - os outsiders das camadas dominantes da sociedade.

$2^{\circ}$ ) à "Psicologia das Minorias Ativas", pois ao representar um grupo o sujeito, neste caso o índio Galdino, e "o mais importante é conhecer as forças que impulsionam a minoria a assumir o risco de ser detestada, rechaçada e saber o que ganha com isso" (MOSCOVICl, 2011, p. 220). Os indivíduos e grupos em minoria, perante um grupo social majoritário, buscam expressão e visibilidade.

Na realidade, os indivíduos gastam uma enorme quantidade de energia para ser exemplo, ou merecedores, da aprovação social. Isto não é uma necessidade vital para as minorias marginais, desviantes, 
porém ativas. À custa de qualquer sacrifício, sua primeira preocupação é fazer-se visível, alcançar o pleno reconhecimento de sua existência aos olhos da maioria e na mente de quem representa esta maioria. (MOSCOVICl, 2011, p. 221)

A partir destes referenciais é possível entender a complexidade enfrentada ao buscar o desenvolvimento de um projeto cujo objetivo é o de reconhecimento da diversidade étnica e cultural de um grupo, e que permita que todos se reconheçam como indivíduos da mesma espécie, biologicamente falando, e que as diferenças étnicas e culturais sejam respeitadas, e que todos possam aprender e se beneficiar com esta interação.

Numa visão ampla, nas palavras de Edgar Morin (2000, p. 54)

No nível antropológico, a sociedade vive para o indivíduo, o qual vive para a sociedade; a sociedade e o indivíduo vivem para a espécie, que vive para o indivíduo e para a sociedade.

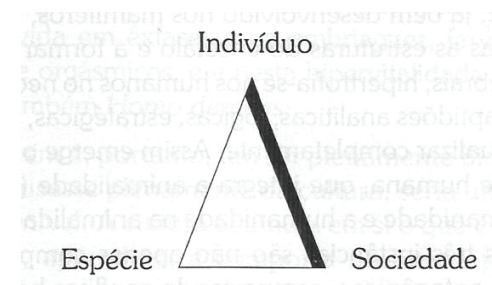

Figura 2 - Representação gráfica da relação do indivíduo com a espécie e a sociedade

Estas palavras fazem refletir que a sociedade que pretendemos construir no futuro depende da forte interação entre o indivíduo e a sociedade, que se estabelece desde a infância, nas escolas, através do que se entende por "forma escolar", estabelecida entre os séculos XVI e XVII (VINCENT; LAHIRE; THIN, 2001, p. 12). Ela surgiu na Europa e que estabeleceu uma relação especial entre um "mestre" e um "aluno", relação esta que passou a ser chamada de "relação pedagógica".

Como toda relação social no espaço e no tempo, a autonomia da relação pedagógica instaura um lugar específico, distinto dos lugares onde se realizam as atividades sociais: a escola. (VINCENT; LAHI; THIN, 2001, p. 13)
Logo, a relação pedagógica adquire um formato onde a relação entre "mestre" e "alunos" são submetidos a regras impessoais estabelecidas pela "ordem pública" num espaço fechado e ordenado, onde o tempo é cuidadosamente regulado e os espaços são preenchidos, submetendo a todos aos "princípios" ou regras que a regem. Com o passar do tempo, esta "forma escolar" foi se aprimorando até os dias atuais, e constitui "o modo de socialização dominante de nossas formações sociais" (VINCENT; LAHI; THIN, 2001, p. 38). As ações propostas e desenvolvidas na escola multiplicam-se e alcançam os pais, comunidade e nas formações das instituições, nos estágios de "inserção", etc. A "forma escolar" se impôs como um padrão de referência como um meio, legítimo e dominante, de socialização.

Entretanto, este modelo vem sendo alvo de numerosos debates sociais, pois contém em si os conceitos de "mestre" e "aluno", ou seja, alguém que ensina para alguém que aprende de acordo com o que é estabelecido pela "ordem pública". O "aluno" hoje é visto como alguém que também detém saberes e que pretende compartilhar com os outros "alunos" e com os "mestres". Quer opinar e esclarecer suas dúvidas, numa relação dialógica, diferente daquela que foi estabelecida na concepção histórica da "forma escolar". As ações hoje estão voltadas para escolas mais "voltadas para o exterior" ou aquelas que convidam pais, comunidades e outras instituições a serem coparticipes em seus propósitos.

\section{2 - DIREITOS HUMANOS NA ESCOLA E O RECONHECIMENTO DAS DIFERENÇAS INDIVIDUAIS: ÉTNICAS E CULTURAIS}

Tratado sem alma e afecto, como objecto de manipulação desmesurada, o mundo natural encontra-se hoje ameaçado por múltiplas agressões, impondo ao ser humano a assunção de limites éticos, sem os quais não é possível a partilha solidária do tempo e do espaço. (BAPTISTA, 2008, p.7)

A convivência solidária e respeitosa dos espaços ao longo do tempo leva à ampliação de saberes entre os habitantes de um determinado ambiente, seja natural ou urbano. A preservação dos ambien- 
tes naturais pode ser facilmente ser ensinada por seus habitantes de longa data, da mesma forma que o ambiente urbano tem regras de convívio social que se constroem ao longo do tempo. Quando habitantes do ambiente natural estabelecem o diálogo com habitantes do ambiente urbano, os saberes podem ser compartilhados, o que irá permitir o entendimento de cada uma destas diferentes realidades e o trânsito irrestrito nestes ambientes, numa perspectiva de cidadania consciente e responsável.

\section{Justificativa e apresentação do tema escolhido:}

Os povos indígenas que ocupavam desde longo tempo o território que hoje conhecemos como "Brasil" mantinham seus hábitos de ocupação e preservação do ambiente natural de forma bastante intensa, mesmo que baseada na oralidade, conforme a eles se refere Carlos Alberto Ricardo:

Sequer sabemos os seus nomes. Os povos indígenas que viviam no que veio a se chamar Brasil eram ágrafos e atualmente a maioria não domina a leitura e a escrita. Foram - e continuam sendo "batizados" por escrito por "brancos", antes mesmo que alguém lhes compreendesse a língua. (RICARDO, 1995, p. 32)

Desde então, a ocupação do território por levas de estrangeiros das mais diferentes etnias demonstrou dificuldade em se adaptar a este ambiente recém-ocupado de forma tão respeitosa quanto seus habitantes originais. Além disso, sofreram a mesma dificuldade de interação sociocultural pela diversidade linguística, marca característica de cada uma das etnias consideradas.

Considerando a escola o principal local onde ocorre "o modo de socialização dominante de nossas formações sociais" (VINCENT; LAHIRE; THIN, 2001, p. 38), este trabalho focalizou nem tanto a escola, como o todo, mas as ações desenvolvidas em sala de aula perante uma turma de alunos, ações estas voltadas para o reconhecimento de suas identidades e compartilhamento de saberes socialmente construídos.

\section{Caracterização da escola}

\section{a) Histórico}

A EMEF Bernardo O'Higgins está localizada bem próxima à Diretoria Regional de Educação de Santo Amaro, da rede municipal da Prefeitura de São Paulo. Disso pode-se dizer que é uma escola bastante antiga, cuja cultura reflete a história e desenvolvimento do bairro desde as suas origens. O seu projeto de construção original foi sendo ampliado e modificado com o passar do tempo, tendo ganhado um prédio anexo que contém um auditório, a Sala de Informática Educativa e algumas salas de aula. O que se ganhou no acolhimento de mais alunos, em busca de uma educação de qualidade, representada pela readequação de seus objetivos educacionais, perdeu-se na redução dos espaços livres de circulação, de lazer e recreação, ou dedicados à prática de modalidades esportivas diferenciadas.

O bairro de Santo Amaro, que décadas atrás teve uma das poucas linhas de bonde da cidade, desenvolve-se no polo que é hoje, que dispõe de uma rede de avenidas e o terminal da primeira linha de metrô da capital. Estes são alguns fatores que indicam seu crescimento significativo, e esta mudança é visível nesta escola. A busca constante da qualidade do ensino pela equipe de gestão e docentes é visível, o que torna a busca por vagas bastante disputada. Nesta condição, as identidades individuais se mesclam em busca de interesses coletivos, num ambiente marcado pela presença de fluxos migratórios em busca de emprego nas recentes obras públicas, reflexo do deslocamento de famílias inteiras, no processo de urbanização das regiões periféricas da metrópole.

\section{b) 0 espaço escolar}

O espaço escolar, desde a sua fundação, foi sendo cada vez mais explorado e compartimentado. De um único prédio, de sua construção original, a demanda da comunidade por mais vagas acabou por se construir um prédio anexo. Os espaços de lazer originais foram reduzidos e, consequentemente, o lazer dos alunos menores um pouco restrito. 
Atualmente, é possível referir que no prédio original ficam, no andar térreo as salas da equipe de gestão, secretaria e serviço de atendimento ao público. Estas dependências estão alocadas em torno de um hall central, que dá acesso a um sanitário para estes funcionários. Este hall dá acesso a um pátio coberto, no qual são servidos os lanches e refeições, e uma escada leva a dois pavimentos superiores, de uso comum do corpo docente e discente, especialmente dos adolescentes. No primeiro andar está situada a Sala dos Professores, que tem anexos sanitários exclusivos e uma pequena copa. Tem ainda seis salas de aulas, com tamanhos e mobiliários diferenciados, que atendem a fins específicos. No segundo andar, sobre a sala dos professores está localizada a sala de Leitura; as salas de aula seguem o mesmo padrão do andar inferior.

Do pátio coberto, tem-se o acesso à quadra poliesportiva coberta e algumas áreas descobertas, que a recente equipe de gestão vem equipando de forma $a$ atender às brincadeiras infantis. Dele se tem também acesso ao prédio anexo onde estão localizados o Auditório, a Sala de Informática no térreo e nos dois andares superiores salas de aula que atendem principalmente os alunos das séries iniciais, com mobiliário que atende ao público infanto-juvenil.

Em vários locais da escola encontram-se murais com avisos para as pessoas que nela circulam: no hall da entrada do prédio, na sala dos professores e avisos em algumas paredes, nas quais os alunos costumam buscar informações. Tanto no interior das salas de aulas, quanto nos corredores de circulação dos alunos, são comuns as exposições dos trabalhos de pesquisas requisitados pelos professores, de tempos em tempo. Na época de Feira Cultural no segundo semestre, os espaços da escola são ocupados quase que em sua totalidade, pelas melhores produções dos alunos durante todo o ano, ou produzidas para este fim.

É uma escola bem situada, próxima à Diretoria de Ensino, o que faz com que algumas vezes, alguns encontros de capacitação nela ocorram. Isto faz com que muitos alunos, especialmente os que residem em seu entorno, a valorizem, poiséum marco educacional no bairro.

\section{c) 0 tempo escolar}

O tempo nesta escola dá mostra em suas paredes, em sua forma e na sua utilização. É um tempo multidimensionado, pois tem de abarcar a condição multifacetada dos aspectos que atende: do $1^{\circ}$ ao $9^{\circ}$ ano do ensino regular, em dois turnos diurnos e, no período noturno, aos alunos da EJA.

Atender ao mesmo tempo todas estas demandas tem levado a equipe de gestão a utilizar, além dos pequenos avisos entregues aos alunos na forma impressa, um jornal periódico e também mensagens que utilizam as modernas tecnologias de informação e comunicação. Desta forma, os acontecimentos vividos pela comunidade escolar dentro e fora de seus muros, seus projetos em vias de realização e resultados alcançados neles são compartilhados entre a equipe de gestão, corpo docente, funcionários e todos os alunos dos três turnos em que funciona a escola.

De uma forma geral, os professores e alunos atendem a um sinal sonoro padrão nas escolas, tanto para entrada quanto saída, além do início e término das aulas, e intervalo para merenda. Os inspetores de alunos, nos corredores, acompanham as trocas das aulas e dão informes, quando necessários, de qualquer alteração que tenha ocorrido.

\section{d) Normas e Regulamentos}

A escola segue, de forma geral, os regimentos e normas ditados pelos órgãos federais, estaduais e municipais de Educação. Na medida da autonomia oferecida pela legislação, e atendendo às peculiaridades da "forma escolar" (VINCENT; LAHIRE; THIN, 2001) a equipe de gestão discute, dentro dos princípios da "gestão democrática" os interesses e objetivos mais significativos aos alunos, seus pais e comunidade atendida. Reconhece ainda, em cada aluno a sua condição física, familiar e sociocultural nas diversas intervenções que realiza diariamente, de tal forma que as regras institucionais e próprias desta escola acabam sendo transformadas em ações que garantem os direitos individuais e coletivos na instituição. 


\section{e) Práticas escolares}

Em uma escola com tal diversidade de profissionais e alunos, as práticas escolares se multiplicam, sendo cada uma única e personalizada. É possível encontrar nela docentes recém-egressos dos cursos universitários com práticas inovadoras e profissionais em fim de carreira, respeitados e valorizados por seus alunos, e que utilizam convictamente metodologias que conquistaram da prática ao longo de muitos anos de trabalho.

A equipe gestora sabe que lida com esta diversidade e também se multiplica em esforços para a todos contentar, tendo em vista o sucesso da escola, que se expressa nos índices favoráveis do processo de ensino-aprendizagem de seus alunos.

No desenvolvimento destas ações podem ser relacionadas diversas instâncias onde os indivíduos se expressam, manifestando suas opiniões e colocando-as em votação, em um processo democrático:

- Reuniões Pedagógicas

- Reuniões de Conselho de Classe

- Reuniões da Associação de Pais e Mestres

- Reuniões com Pais ou Responsáveis
- Reuniões de Conselho de Escola

- Eleição e encontros com o Grêmio Estudantil

- Desenvolvimento dos Projetos Especiais de Ação (PEA)

\section{f) A sala de aula e sua distribuição espacial}

As salas de aula contam com mobiliário padronizado, fornecido pela Prefeitura, que além da lousa e respectivo aparador, dispõe de mesa e armário para disposição do material docente, e 35 carteiras para acomodação dos alunos, dispostas costumeiramente em seis fileiras, cada uma com cinco ou seis carteiras. (Figura 3). Isto difere das salas destinadas aos Programas Especiais da Secretaria Municipal de Educação, tais como exemplo o dos "Espaços e Salas de Leitura" e também o de "Informática Educativa". Em Bittencourt (2015) é possível encontrar um estudo preliminar que aponta as diferenças entre as salas de aula padronizadas e a de uma Sala de Leitura em uma outra escola da rede municipal de ensino da cidade de São Paulo. As principais diferenças encontradas foram sintetizadas de acordo com o Quadro 2, a seguir:

\begin{tabular}{|c|c|}
\hline Sala de Aula & Sala de Leitura \\
\hline 35 carteiras individuais & 6 ou 7 mesas coletivas \\
\hline Lousa & Equipamento de multimídia \\
\hline $\begin{array}{c}\text { Poucos livros, didáticos ou paradidáticos, } \\
\text { utilizados sob orientação direta do(a) } \\
\text { Professor(a) }\end{array}$ & $\begin{array}{c}\text { Muitos livros cuja leitura é proposta pelo } \\
\text { Professor(a), mas de livre acesso dos } \\
\text { alunos }\end{array}$ \\
\hline $\begin{array}{c}\text { Interatividade preferencial entre } \\
\text { Professor-Aluno }\end{array}$ & \begin{tabular}{c} 
Interatividade preferencial Aluno-Aluno \\
\hline
\end{tabular} \\
\hline
\end{tabular}

Quadro 2 - Principais diferenças entre uma sala de aula regular e uma Sala de Leitura (BITTENCOURT, 2015, p. 48) 
Nas salas de aulas padronizadas, no início do ano letivo, os alunos costumam acomodar-se de acordo com os laços de amizade pré-estabelecidos, mas este arranjo pode ser modificado ao longo do ano letivo de acordo com o interesse tanto do "mestre" quanto dos "alunos" (VINCENT; LAHIRE; THIN, 2001), ou as necessidades explícitas em alguma técnica a ser desenvolvida pelos professores em suas aulas.

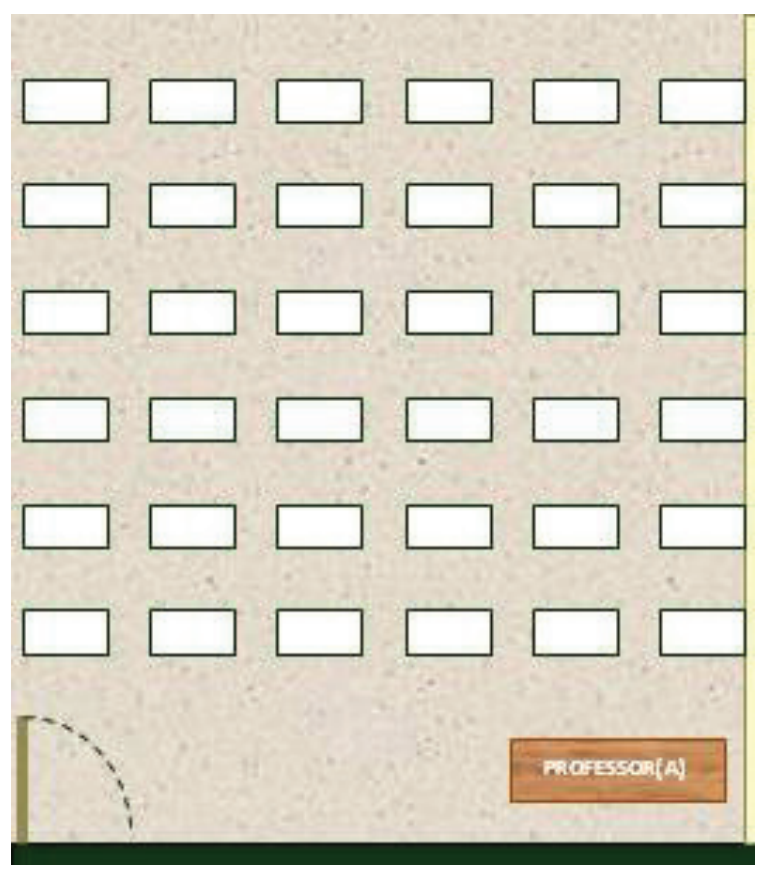

Figura 3 - Característica geral da disposição do mobiliário em uma sala de aula

Muitas vezes os professores rearranjam esta disposição padronizada organizando as carteiras em um grande círculo, para as discussões coletivas da turma, ou em duplas ou em "pequenos grupos" de 3 a 5 carteiras, dependendo da tarefa a ser executada e do número de alunos envolvidos na sua execução. Esta é uma tarefa do professor, que promove a modificação do ambiente da sala de aula e proporciona dinamismo as suas aulas ao longo de todo um ano letivo (DOYLE, 1996, p. 394).

As condutas sociais que se expressam em sala de aula tiveram seu estudo iniciado por William MacDougall (1871-1929), que publicou o primeiro livro sobre o assunto com o título: "An introduction to social psychology", mas o grande pesquisador sobre a matéria tem sido considerado Kurt Lewin (1890-
1947), que deu ênfase ao estudo dos pequenos grupos. Kurt Lewin propôs ainda a existência do "psico-grupo", como aquele formado por interesses relacionados às afinidades entre seus, diferente do "sócio-grupo", que seria o grupo incumbido de uma determinada tarefa. (MAILHIOT, 2013, p. 31).

\section{g) O Projeto Pedagógico em sala de aula}

No início de cada ano letivo uma dupla de professores recebe da equipe de gestão a incumbência de acompanhar uma turma de alunos com maior atenção, escutando seus anseios e reivindicações, propondo articulação de seus interesses perante a equipe de gestão e propondo ações diferenciadas que se fizerem necessárias em sala de aula. Atendendo a este princípio de gestão democrática, são eleitos dois alunos que serão os representantes da turma para os procedimentos rotineiros de interlocução com a equipe gestora, mesmo na ausência dos professores responsáveis pela turma.

Estes alunos representantes participam de encontros regulares com a equipe de gestão para discutir os interesses de seus colegas, numa ação de "representação social" (JOVCHELOVITCH, 2003) que os prepara, e a todo o grupo, para o diálogo e defesa de seus interesses, tanto em condições de "maioria" quanto de "minorias ativas" (MOSCOVICI, 2011). A representação democrática transforma a "forma escolar" (VINCENT; LAHIRE; THIN, 2001), paulatinamente, em uma instituição que reflete a sociedade que se transforma tanto no espaço quanto no tempo considerado.

\section{3 - DESENVOLVIMENTO DE UM PROJETO DE INTERVENÇÃO COM UMA TURMA DE ALUNOS DE NONO ANO DO ENSINO FUNDAMENTAL}

Seja como for, a forma como categoria de pensamento foi considerada de modo bastante preciso por Aristóteles. Não [devemos] considerar a forma de um objeto tal como se apresenta aos olhos: estática, definitiva, ou solidificada, se preferirmos, mas, sim, a forma que expressa a mutação, que expressa a evolução e, portanto, que expressa o tempo. (NOËL, 1996, p. 16) 
A forma como categoria do pensamento foi interpretada como "forma escolar", estabelecida entre os séculos XVI e XVII (VINCENT; LAHIRE; THIN, 2001) e que vem sendo aperfeiçoada ao longo do tempo. Tanto a escola EMEF Bernardo O ' Higgins, apresentada em seus vários aspectos no Capítulo anterior, quanto à comunidade que a compõe, vem sofrendo contínuas transformações e promovendo modificações na "forma escolar" que ocupa.

A relação pedagógica, entendida como aquela que se estabelece "mestre" e "alunos" em um projeto de intervenção, deve atentar que tanto "mestre" quanto "alunos" são indivíduos com características individuais próprias, que devem ser consideradas. Relembrando o estudo de Bernadete Angelina Gatti sobre a heterogeneidade existente entre os professores e inúmeros fatores que compõem sua identidade profissional (GATTI, 1996), é preciso reiterar que este projeto foi elaborado e desenvolvido tendo em vista os conhecimentos adquiridos e acumulados durante a prática profissional de longas décadas em sala de aula desta profissional. Outros profissionais, com identidades pessoais e profissionais diversas, certamente teriam produzido um trabalho bastante diferente.

Depois destas considerações, é possível indicar, rapidamente, os principais aspectos que compõem a ação interventiva focada no reconhecimento das diferenças étnicas e culturais entre os alunos de uma turma de alunos do $9^{\circ}$ ano e promoção do respeito a esta diversidade, numa perspectiva da Educação em Direitos Humanos.

\section{Apresentação}

Para o melhor desenvolvimento do Projeto Pedagógico, especialmente no que se refere ao desenvolvimento das práticas democráticas por parte dos alunos, teoricamente referida na "teoria das representações sociais" (JOVCHELOVITCH, 2003), conforme foi estudado o "Projeto Pedagógico em sala de aula", no Capítulo 2. Neste documento consta como objetivo da Proposta Pedagógica para o corrente ano letivo:

Desenvolver uma relação ética e diversificada com práticas voltadas para o respeito às diferenças e para a superação dos preconceitos e discriminações, introduzindo no currículo ações que possibilitem a reflexão sobre a diversidade e torne perceptíveis as potencialidades humanas.

A partir das reflexões teóricas percebidas durante este Curso de Educação em Direitos Humanos, associadas aos conhecimentos acumulados durante a prática profissional e manejo da sala de aula, foram planejadas e desenvolvidas as ações relatadas, bem como os resultados e a avaliação pelos próprios participantes.

A turma selecionada para o desenvolvimento do "projeto de pesquisa-intervenção" (DAMIANI et all., 2013) é composta por 29 alunos matriculados, sendo 16 do sexo feminino e 13 do sexo masculino nascidos entre abril/2000 e dezembro/2002. Para salvaguardar as identidades destes alunos, considerados "adolescentes", de acordo com o Estatuto da Criança e do Adolescente (Lei n 8.069, de 13/07/1990) serão sempre referidos pelo número de chamada do Diário de Classe da Escola.

\section{Justificativa}

A proposta de intervenção decorrente deste Projeto de Pesquisa foi desenvolvida na identificação das diferentes identidades dos grupos étnicos e culturais que compõem o corpo docente da escola. Lançando um olhar abrangente sobre os alunos em uma classe ou em um evento escolar mais amplo, tanto a equipe de gestão quanto o corpo docente pouco conseguem observar da diversidade que se encerra em cada aluno ou aluna. Sentados ou brincando, usando uniformes ou usando suas vestes cotidianas, a visão de conjunto supera o reconhecimento das origens étnicas das crianças e jovens que frequentam a escola.

\section{Objetivo}

Incrementar o relacionamento respeitoso entre os alunos, reconhecendo as diferenças individuais, dadas pela diversidade étnico-cultural, através da promoção de ações colaborativas entre os estudantes que produzam boas práticas escolares e sociais. 


\section{Metodologia de Trabalho}

Os alunos, sabedores da Proposta Pedagógica da escola e empenhados em alcançar este objetivo, dispuseram-se de bom grado a participar das ações propostas pela professora, o que configura este projeto como uma "pesquisa-ação", que corresponde, segundo Thiollent (2011, P. 20), a:

A pesquisa-ação é um tipo de pesquisa social com base empírica que é concebida e realizada em estreita associação com uma ação ou com a resolução de um problema coletivo e no qual os pesquisadores e os participantes representativos da situação ou do problema estão envolvidos de modo cooperativo ou participativo.

De acordo com esta concepção, o primeiro passo do projeto aconteceu através de um levantamento de dez questões de múltipla escolha a serem respondidas individualmente. Cada questão continha quatro alternativas, cada uma delas acompanhada de um espaço para que os alunos assinalassem a alternativa de sua escolha. As alternativas ofereciam, para questões gerais de caráter étnico e cultural, alternativas que atendiam a diferentes culturas nos aspectos de palavras utilizadas, alimentos consumidos com maior frequência, ritmos musicais e artistas preferidos. Tendo em mãos estes questionários, pode ser feita a tabulação das respostas, com o uso de uma planilha eletrônica que indicou respostas coincidentes entre os alunos, o que poderia indicar interesses comuns, tanto de origem étnica quanto cultural.

A partir da análise destas indicações, foram formados nove "pequenos grupos", do tipo "psico-grupo", conforme conceituados por Mailhiot (2013). Tendo em vista a identificação dos interesses comuns dos nove "pequenos-grupos", foram selecionados nove textos, buscados em páginas de interesse geral da internet. Depois de uma semana que responderam as dez questões iniciais, os nove "pequenos-grupos" foram convidados a se sentarem juntos, pela aproximação das carteiras da classe (Figura 4). A partir deste rearranjo eles foram orientados a fazer a leitura compartilhada dos textos previamente escoIhidos, buscando sua interpretação, troca de informações e registro das opiniões surgidas durante a discussão. Ao receber esta tarefa e se dedicar a sua realização, os alunos deixam de ser definidos como "psico-grupos" e passam a ser reconhecidos como "sócio-grupos".

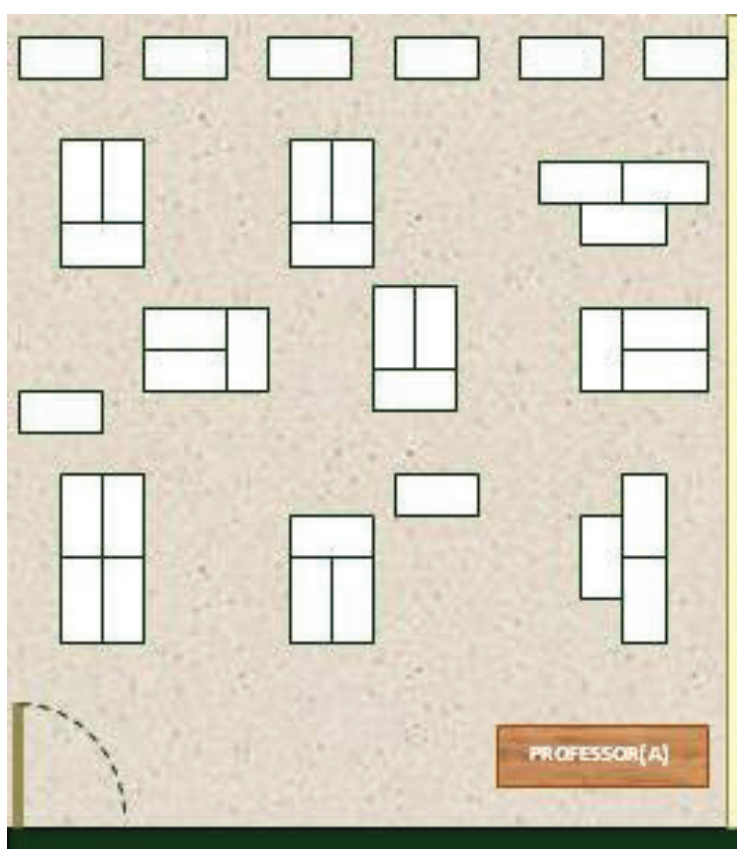

Figura 4 - Disposição das carteiras durante o trabaIho dos "pequenos grupos"

Ao se organizarem para a tarefa em "pequenos grupos", alguns alunos deixaram de seu lugar original dentro da classe e foram ocupar outro lugar onde a carteira tivesse sido desocupada, para se aproximar dos colegas com os quais iriam compartilhar a tarefa. Esta mudança passou despercebida a todos até a finalização da tarefa, mas ao final da aula, de 45 minutos, a professora pediu que realinhassem as carteiras de toda a classe em seis fileiras, conforme a organização original, e que os alunos se mantivessem sentados nestes novos lugares. Houve admiração de todos, por terem migrado para um novo local na classe, algumas vezes distante ao que ocupavam anteriormente e distantes dos colegas com os quais estavam acostumados a conversar. A partir deste momento os antigos "psico-grupos" se desfizeram e a disposição dos alunos na classe passou a ser determinada pelo arranjo determinado pela tarefa em que os pequenos grupos desenvolveram em uma condição de "sócio-grupos", ou seja, envolvidos na resolução de uma determinada tarefa, mesmo que com 
colegas com os quais estava desacostumado de conversar e compartilhar impressões.

A nova disposição dos alunos nas carteiras da classe foi registrada pela professora e ficou estabelecido que respeitariam este rearranjo dali por diante. A classe, que estava disposta, desde o início do ano num arranjo oferecido simplesmente por aproximações sociais fortuitas, definidas por "psico-grupos", passou para uma distribuição originada por uma dinâmica vinculada à realização de uma tarefa, o que transformou os antigos "psico-grupos" em "sócio-grupos", vinculados pelas características individuais, mas com aproximações melhor definidas, que favoreceram a realização de uma tarefa escolar.

\section{Cronograma}

Maio/2016 - Aplicação das questões iniciais e análise geral dos resultados.

Junho/2016 - Aplicação da dinâmica que resultou no rearranjo dos alunos na classe. Avaliação dos resultados pelos alunos e pelos professores.

\section{Recursos materiais}

Presencialmente: cópias do questionário inicial e dos textos trabalhados pelos "pequenos grupos".

Nas ações de planejamento pela professora: computador com acesso à internet e com os recursos oferecidos por um editor de texto e uma planilha eletrônica.

\section{4 - ANÁLISE E RESULTADOS PARCIAIS DO PROJETO DE INTERVENÇÃO COM UMA TURMA DE NONO ANO DO ENSINO FUNDAMENTAL E OBTIDOS COM OUTRAS TURMAS}

Conviver é chegar a viver juntos entre distintos sem os riscos da violência e com a expectativa de aproveitar de maneira fértil nossas diferenças. $O$ desafio da convivência é basicamente o desafio da tolerância à diversidade e esta encontra sua manifestação mais clara na ausência da violência.

(MOCKUS, 2002, p. 94)
Depois de algumas semanas, a maioria dos alunos ainda se mantinha nos novos lugares conquistados, estreitando laços de coleguismo recém-conquistados. Como forma de finalização desta primeira etapa, a professora realizou uma pesquisa breve para se informar da avaliação que os alunos poderiam oferecer desta experiência. Foi dado a cada aluno um fragmento de papel branco, de aproximadamente sete centímetros de lado, onde puderam desenhar, simplesmente, os emoticons, com os quais estão bastante acostumados por causa da linguagem mediática que compartilham, que representavam seu grau de satisfação com as ações desenvolvidas no projeto. Os desenhos traçados pelos alunos foram juntados e estão contidos na Figura 4, abaixo:

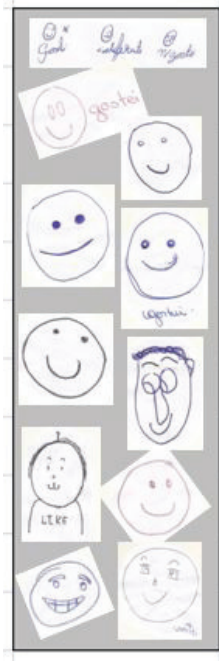

GOSTEI

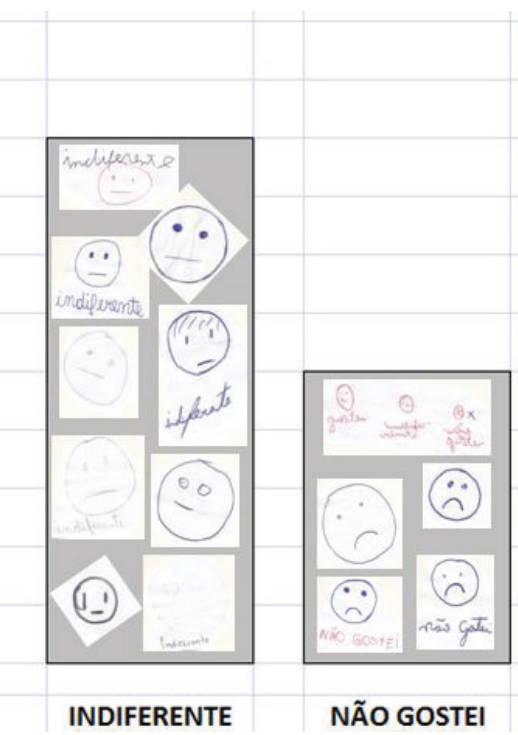
satisfação dos alunos com os resultados obtidos neste projeto

A reorganização dos alunos a partir da proposta de uma atividade diferenciada, que buscava identificar a diversidade étnica e cultural dos alunos, acabou proporcionando alguns resultados, que foram perceptíveis pelos professores que atuam perante esta turma:

$1^{\circ}$ ) Os alunos que mantiveram sua nova posição na classe, aproximando-se dos colegas com os quais criaram novos vínculos, demonstraram satisfação nesta mudança pela conquista de novas amizades. 
$2^{\circ}$ ) O relacionamento entre os colegas da classe passou a ser mais harmonioso e o desempenho da turma nas tarefas tornou-se mais produtivo.

$3^{\circ}$ ) A dinâmica de toda a classe ao se decidir em torno de novas propostas, ou tarefas dos professores, passou a ser recebida com maior entusiasmo do que anteriormente, e passaram a ser realizadas mais rapidamente.

Quanto ao material produzido, o questionário proposto inicialmente, já durante sua aplicação os alunos tiveram dúvida quanto à elaboração das alternativas de três questões. Na revisão feita tanto pela Coordenação da Escola quanto pela Orientadora do projeto foram apontadas sugestões aplicáveis a uma reelaboração das mesmas.

Convém notar que estes resultados foram obtidos perante uma das turmas de $9^{\circ}$ ano regular, do período da manhã, mas se torna importante insistir que outros professores desenvolveram também suas propostas, adequadas à realidade de suas turmas. Outros projetos, também com turmas de $9^{\circ} \mathrm{s}$ anos, foram desenvolvidos dentro da Proposta Pedagógica da escola, dinamizando as ações voltadas para a valorização da diversidade étnica e cultural dos alunos, e elaboração, até o final do ano do Trabalho Colaborativo de Autoria (TCA).

\section{CONSIDERAÇÕES FINAIS:}

As reflexões teóricas apresentadas nos dois primeiros capítulos poderão servir de referências a futuros estudos e desenvolvimentos de projetos mais conclusivos, dentro deste e de outros campos de estudos que envolvam o "modelo escolar" vigente, e que se expressa atualmente em diversas instituições, além das escolas propriamente ditas, como a focalizada aqui.

Com a aplicação do questionário inicial foi possível identificar, além dos indígenas e seus descendentes, também estrangeiros, ou seus descendentes, de outras partes do mundo. Apesar da precariedade dos resultados e da exiguidade do tempo para realização desta pesquisa-intervenção, os resultados obtidos superaram as expectativas iniciais da pesquisadora, o que demonstra que a dinâmica da sala de aula muitas vezes é mais rica do que podemos supor, à primeira vista.
O questionário inicial, que foi elaborado com o objetivo de se identificar a origem étnica e cultural dos alunos teve a resposta de algumas questões descartada na avaliação, por erro na formulação ou falta de conhecimentos por parte dos alunos. A partir dos resultados obtidos e da ação que envolveu o rearranjo dos alunos na classe, foi possível imaginar que a elaboração do questionário poderia ser feita a partir de quaisquer outras questões do cotidiano, tais como: cor de roupa preferida, ritmo musical que prefere ouvir, ocupação das horas de lazer. $\mathrm{O}$ foco da pesquisa tem de estar relacionado com a realidade cotidiana dos alunos da comunidade considerada e as questões deverão ser elaboradas de forma a permitir o agrupamento dos alunos em torno de preferências ou situações reais de seu cotidiano. A análise dos resultados obtidos nos questionários deve privilegiar as questões que envolvem poucos alunos, desconsiderando aquelas que refletem a aspiração da maioria. As preferências dos alunos introvertidos, ou que tenham poucas relações sociais dentro da classe, devem ser observadas com detalhe, de forma a criar ao seu redor um "sócio-grupo" com quem este aluno possa se relacionar na realização da tarefa, e estabelecer com estes colegas novos laços de relacionamento.

Finalizando, é possível considerar ainda duas questões que merecem reflexão. A primeira se refere à "forma escolar": a ordem das carteiras favorece a interatividade entre os alunos e maior cooperação no ambiente da sala de aula. A segunda remete ao fato de que a escola, em seu projeto pedagógico, tem como tema principal o reconhecimento e respeito às diversidades. A "diversidade" remete à "diferença" que existe entre os indivíduos. O símbolo matemático que expressa o "diferente" corresponde a dois pequenos segmentos de reta cortados obliquamente. Se for retirado o corte oblíquo, surge o sinal de "igual", que representa a "igualdade", e que se assemelha também uma "ponte" entre o "eu" e o "outro". Neste trabalho, ao tratar do reconhecimento e respeito às diferenças individuais, o caminho que foi percorrido foi o de encontrar as "semelhanças", ou "igualdades", entre os alunos e a partir delas estabelecer "pontes" de relacionamento entre o "eu" e o "outro", surgindo então novas relações de relacionamento respeitoso, numa perspectiva dos Direitos Humanos. 


\section{REFERÊNCIAS BIBLIOGRÁFICAS}

BAPTISTA, Isabel. Hospitalidade e eleição intersubjectiva: sobre o espírito que guarda os lugares. Rev. Hospitalidade, Ano V, n. 2, Dez. 2008. Disponível em: https://revhosp.org/ hospitalidade/article/viewFile/150/175 Visualizada em 19/04/2016.

BECKER, Howard S. Outsiders: estudos de sociologia do desvio. Trad. Maria Luiza X. de Borges. Ver. tec. Karina Kuschnir. Rio de Janeiro: Zahar, 2008.

BENEVIDES, Maria Victoria de Mesquita. O desafio da educação para a cidadania. in: AQUINO, Julio Groppa (Coord.) Diferenças e preconceito na escola: alternativas teóricas e práticas. São Paulo: Summus, 1998.

BITTENCOURT, Elizabeth Christina R. Hospitalidade na Sala de Leitura em uma escola municipal da cidade de São Paulo. Dissertação de Mestrado em Hospitalidade. 2015. Disponível em: http://portal.anhembi.br/wp-content/uploads/ dissertacoes/hospitalidade/2015/Dissertacao_Elisabeth_ Christina_Rodrigues_Bittencourt.pdf Visualizada em 03/07/2016.

CARBONARI, Paulo César et all (Org.) Educação em Direitos Humanos: sistematização de práticas de educação básica. Passo Fundo: IFIBE, 2014.

CHIZzOTTI, Antonio. Pesquisa em Ciências Humanas e Sociais. 4 ed. São Paulo: Cortez, 2000.

CASTRO, Eduardo Viveiros de. Histórias ameríndias. In: Novos estudos $n^{\circ} 36,1993$. Disponível em: http://novosestudos.uol.com.br/v1/files/uploads/contents/70/20080625_ historia_dos_indios.pdf Visualizada em 02/07/2016.

CUNHA, Manuela Carneiro da. Índios no Brasil: história, direitos e cidadania. São Paulo: Claro Enigma, 2012.

DAMIANI, Magda Floriana et all. Discutindo pesquisas do tipo intervenção pedagógica. Cadernos de Educação, Pelotas, n. 45, p. 57-67, mai./ago. 2013. Disponível em: https:// periodicos.ufpel.edu.br/ojs2/index. php/caduc/article/ view/3822/3074 Visualizada em 29/05/2016.

DOYLE, Walter. Classroom organization and management. in: Handbook of research for educational communications and technology: a project of the Association for Educational Communications and Technology. New York: Mac Millan, 1996.p. 392-431.

FERRAZ JUNIOR, Tercio Sampaio. A demarcação de terras indígenas e seu fundamento constitucional. In: Revista Bras. Direito Constitucional. №3, jan/jun 2004. Disponível em: www.esdc.com.br/seer/index. php/rbdc/article/download/92/91 Visualizada em 02/07/2016.
GATTI, Bernadete Angelina. Os professores e suas identidades: o desvelamento da heterogeneidade. Cad. Pesq. , São Paulo, n. 98 p. 85-90, ago. 1996.

GIL. Antonio Carlos. Métodos e técnicas de pesquisa social. 6 ed. São Paulo: Atlas, 2008.

IBGE. Censo demográfico 2010: Características gerais dos indígenas, resultados do universo. Rio de Janeiro: IBGE, 2010. Disponível em: http://biblioteca.ibge.gov.br/visualizacao/periodicos/95/cd_2010_indigenas_universo.pdf Visualizada em 21/04/2016.

JOVCHELOVITCH, Sandra. Vivendo a vida com os outros: intersubjetividade, espaço público e representações sociais. in: GUARESCHI, Pedrinho A; JOVCHELOVITCH, Sandra (Orgs.) Textos em representações sociais. 8 ed. Petrópolis, RJ: Vozes, 1995.

KANT, Emanuel. Crítica da razão prática. Trad. Afonso Bertagnoli. Digitalização da edição em papel da Edições e Publicação Brasil Editora S/A. São Paulo, 1959. (C) 2004 - Emanuel Kant. Disponível em: http://www.ebooksbrasil.org/ eLibris/razaopratica.html Visualizada em 23/04/2016.

MAILHIOT, Gérald Bernard. Dinâmica e gênese dos grupos: atualidade das descobertas de Kurt Lewin. São Paulo: Vozes, 2013.

MEC/SEF. Parâmetros Curriculares Nacionais: terceiro e quarto ciclos: apresentação dos temas transversais. Brasília: Ministério da Educação/Secretaria de Educação Fundamental, 1998.

MOCKUS, Antanas. Convivência como harmonização da lei, da moral e da cultura. In: BRASLAVSKY, Cecília. Aprender a viver juntos: educação para a integração na diversidade. Trad. José Ferreira. Brasília: UNESCO, IBE, SESI, UnB, 2002.

MORIN, Edgar. Os sete saberes necessários à educação do futuro. Trad. Catarina Eleonora F. da Silva e Jeanne Sawaya. Ver. téc. Edgard de Assis Carvalho. São Paulo: Cortez; Brasília: UNESCO, 2000.

MOSCOVICl, Serge. Psicologia das minorias ativas. Trad. Do Grupo de Leitura "Ideologia, Comunicação e Representações Sociais"; responsável Pedrinho Guareschi. Petrópolis: Vozes, 2011.

NOËL, Émile. As ciências da forma hoje. Trad. Cid Knipel Moreira. Campinas: Papirus, 1996.

OLIVEIRA, Avelino da Rosa. Exclusão social: o que ela explica? in: VALLE, Lilian do (Org.) O mesmo e o outro da cidadania. Rio de Janeiro: DP\&A, 2000.

PIUBELLI, Rodrigo, Memórias e imagens em torno do índio pataxó Hãhãhãe Galdino Jesus dos Santos (1997- 
2012).2012. 138 p. Dissertação (Mestrado em História) Universidade de Brasília. Brasília. Disponível em http://repositorio.unb.br/bitstream/10482/11836/1/2012_RodrigoPiubelli.pdf. Visualizada em 19/04/2016.

PMSP/SME. Portal da Secretaria Municipal de Educação. Prefeitura do Município de São Paulo / Secretaria Municipal de Educação. Disponível em:

http://eolgerenciamento.prefeitura.sp.gov.br/frmgerencial/ NumerosEscola.aspx? Cod $=095214$ Visualizada em 21/04/2016.

PMSP/SME/FAFE. A diversidade e o Trabalho Escolar. 4 vols. SOUSA, Cynthia Pereira de; CATANI, Denice Barbara (Coord.). São Paulo: FAFE - Fundação de Apoio à Faculdade de Educação, 2006.

RIBEIRO, Darcy. O povo brasileiro: a formação e o sentido do Brasil. 2 ed. São Paulo: Companhia. das Letras, 1995.

RICARDO, Carlos Alberto. "Os índios" e a sociodiversidade nativa contemporânea no Brasil. in: SILVA, Aracy Lopes da; GRUPIONI, Luís Donizete Benzi (Orgs.) A temática indígena na escola: novos subsídios para professores de $1^{\circ}$ e $2^{\circ}$ graus). Brasília: MEC/MAR/UNESCO, 1995.
SEF/SEED/FUNDESCOLA. Índios no Brasil. Documentário, 2013. Disponível em: https://www.youtube.com/watch?v=QQA9wuGgZjl Visualizado em 25/03/2016.

SOUZA, Manoel Nascimento de; BARBOSA, Erivaldo Moreira. Direitos indígenas fundamentais e sua tutela na ordem jurídica brasileira. In: Âmbito Jurídico, Rio Grande, XIV, n. 85, fev 2011. Disponível em: <http://www.ambitojuridico. com.br/site/?n_link=revista_artigos_leitura\&artigo id =8978\&revista_caderno=9>. Acesso em jan 2016.

SZTUTMAN, Renato (Org.). Eduardo Viveiros de Castro - Série Encontros. Rio de Janeiro: Azougue, 2008. Disponível em: http://www.agrodrought.ei.udelar.edu.uy/wp-content/ uploads/2015/04/Viveiros-de-Castro_2007_Encontros.pdf Visualizada em 02/07/2016.

THIOLLENT, Michel. Metodologia da pesquisa-ação. 18 ed. São Paulo: Cortez, 2011

VINCENT, Guy; LAHIRE, Bernard; THIN, Daniel. Sobre a história e a teoria da forma escolar.In: Educação em Revista, Belo Horizonte, $n^{\circ} 33$, jun/ 2001. Disponível em: http://educa.fcc.org.br/pdf/edur/n33/n33a02.pdf . Acesso em 20/05/2016.

WAISELFISZ, Júlio Jacobo (Coord.) Juventude, violência e cidadania: os jovens de Brasília. São Paulo: Cortez; Brasília: UNESCO, 1998. 